\title{
Estágio Curricular Supervisionado nas licenciaturas em Matemática: reflexões sobre as pesquisas brasileiras
}

\author{
Supervised Curricular Internship in Mathematics degrees: reflections on Brazilian \\ research
}

Anemari Roesler Luersen Vieira Lopes

Maria Auxiliadora Vilela Paiva ${ }^{2}$

Patrícia Sandalo Pereira ${ }^{3}$

Simone Pozebon ${ }^{4}$

Wellington Lima Cedro ${ }^{5}$

\begin{abstract}
Resumo
O presente artigo insere-se no âmbito do projeto "Mapeamento e estado da arte da pesquisa brasileira sobre o professor que ensina Matemática". Tem como principal objetivo mapear, descrever e analisar pesquisas voltadas ao Estágio Curricular Supervisionado, no que tange aos seus objetivos, principais resultados e conclusões. Adotou-se o estado da arte como metodologia e o corpus de análise foi delimitado a partir dos formulários e dos dados tabulados em uma planilha pela equipe executora do referido projeto. Identificaram-se 20 trabalhos que versavam sobre o tema de interesse da pesquisa, que foram analisados tomando-se por base 5 categorias. Dentre os resultados destaca-se o aumento das pesquisas sobre o tema, bem como a compreensão do Estágio como uma etapa que não se restringe à finalização do curso, mas atua como articulador entre a escola de Educação Básica e a Universidade e como um espaço primordial para entender a complexidade da profissão e constituição da identidade docente.
\end{abstract}

Palavras-chave: estado da arte; professor que ensina Matemática; estágio curricular supervisionado.

\footnotetext{
${ }^{1}$ Doutora em Educação pela Universidade de São Paulo (USP). Professora do Departamento de Metodologia do Ensino e dos Programas de Pós-Graduação em Educação (PPGE) e em Educação Matemática e Ensino de Física (PPGEM\&EF) da Universidade Federal de Santa Maria (UFSM). Brasil. Email: anemari.lopes@gmail.com.

${ }^{2}$ Doutora em Matemática pela Pontifícia Universidade Católica do Rio de Janeiro. Professora do Cefor/Reitoria e do Programa de Pós-Graduação em Ciências e Matemática (EDUCIMAT) do Instituto Federal do Espírito Santo (IFES). Brasil. Email: vilelapaiva@gmail.com.

${ }^{3}$ Doutora em Educação Matemática pela Universidade Estadual Paulista Júlio de Mesquita Filho (UNESP). Professora do Instituto de Matemática e do Programa de Pós-Graduação em Educação Matemática (PPGEdumat) da Universidade Federal do Mato Grosso do Sul (UFMS). Brasil. Email: sandalopatricia13@gmail.com

4 Doutoranda em Educação pela Universidade Federal de Santa Maria (UFSM). Brasil. Email: sipoufsm@gmail.com.

${ }^{5}$ Doutor em Educação pela Universidade de São Paulo (USP). Professor do Instituto de Matemática e Estatística e do Programa de Pós-Graduação em Educação em Ciências e Matemática (PPGECM) da Universidade Federal de Goiás (UFG). Brasil. Email: wcedro@ufg.br.
} 


\title{
Supervised Curricular Internship in Mathematics degrees: reflections on Brazilian research
}

\begin{abstract}
This article is part of the project "Mapping and State of the Art of the Brazilian research about the Mathematic's teacher". Its main objective is to map, describe and analyze researches related to the Supervised Curricular Internship, inquiring its objectives, main results and conclusions. The State of the Art was adopted as methodology and the analysis of the corpus was delimited from the forms and the data tabulated in a worksheet by the executing team of the mentioned project. Were identified 20 papers that dealt with the topic of research interest, which were analyzed based on 5 categories. Among the results, highlights the increase in research on the subject, as well as the understanding of the internship as a stage that is not restricted to the end of the course, but acts as an articulator between the Basic Education School and the University and as a fundamental space to understand the complexity of the profession and the constitution of the teaching identity.
\end{abstract}

Keywords: state of the art; mathematics teaching; supervised curriculum internship.

\section{Introdução}

O nosso objetivo geral com este artigo consiste em mapear, descrever e analisar pesquisas voltadas ao Estágio Curricular Supervisionado, no que tange aos seus objetivos, principais resultados e conclusões. Nesse contexto, o corpus de análise foi delimitado com base nas dissertações e teses brasileiras produzidas nos programas de pós-graduação stricto sensu, nas áreas de Ensino e Educação da Capes, no período de 2001 a 2012, que abordam a formação inicial do professor que ensina Matemática (PEM), catalogadas no projeto intitulado: "Mapeamento e estado da arte da pesquisa brasileira sobre o professor que ensina Matemática"6.

Direcionamos nosso enfoque, no primeiro momento, como explicitaremos no percurso metodológico do trabalho, para a formação didático-pedagógica do acadêmico do curso de Matemática, considerando esse um espaço privilegiado da formação, no qual a criatividade e novas aprendizagens ocorrem, e são construídos vários saberes relacionados a teorias e princípios, ao modo de fazer e aprender. Nas licenciaturas, a prática (entendida como disciplina ou como componente curricular) é um dos momentos ou espaços nos quais os conhecimentos didático-pedagógicos podem se articular com saberes dos conteúdos. No entanto, é importante refletir sobre qual é a concepção de prática de que estamos falando. Tomando por base as ideias de Gatti (2012), concebemos a prática como o lugar de

relações profissionais de ensino no qual surgem conhecimentos vitais sobre os processos do exercício da docência com crianças e jovens, é o lugar em que a criatividade docente emerge, é o momento onde não apenas nos defrontamos com uma reprodução estéril, mas com soluções criativas e novas compreensões sobre a relação didática. (p. 18)

\footnotetext{
${ }^{6}$ Projeto aprovado pelo CNPq (486505/2013-8), elaborado pelo GEPFPM, sob a coordenação geral do Prof. Dr. Dario Fiorentini (FE/Unicamp).
} 
Assim, a prática assume esse lugar em que a relação didática se estabelece, e novos fazeres e saberes surgem, tornando-se propício à construção de conhecimentos pedagógicos e de conteúdos.

Há de se destacar que um dos espaços privilegiados para o desenvolvimento da prática dentro do processo formação inicial é o Estágio curricular supervisionado, que se configura como momento de aprendizagem docente. Essa importância é corroborada por Fiorentini e Castro (2003, p. 122), que afirmam que "a prática de Ensino e o Estágio supervisionado podem ser caracterizados como um momento especial do processo de formação do professor em que ocorre de maneira mais efetiva a transição ou a passagem de aluno a professor". Diante disso, nos deteremos a utilizar, como corpus de análise, dissertações e teses que abordam, de alguma forma, o Estágio ${ }^{7}$.

Nesse contexto, é fundamental reconhecer o Estágio como um espaço de aprendizagens, complementar às disciplinas oferecidas em sala de aula, no qual se dá a inserção na realidade escolar, o que permite aprender com a prática dos docentes da escola e com sua experiência, ao interagir e vivenciar ações de ensino e aprendizagem com os alunos. Considerar o Estágio como espaço complementar à formação do licenciando implica compreendê-lo como uma etapa que deve estar presente em todo o processo de formação, articulando teoria e prática.

Assim, se é o estágio que permite ter o conhecimento teórico articulado com a prática - o que será exigido no mundo do trabalho -, então o estágio não é o momento de aplicação do que foi aprendido na teoria, mas a explicitação do vínculo teoria-prática, que é indissociável. (Silva, Vasconcelos, \& Paiva, 2015, p. 128).

O movimento de integrar teoria e prática no processo formativo do aluno, futuro professor, constitui a finalidade do Estágio, considerando, como destacam Pimenta e Lima (2014), o campo de atuação na condição de objeto de análise, de investigação e de interpretação crítica, a partir das relações estabelecidas com as disciplinas do curso. A vivência do Estágio é considerada, assim, um preparo para sua inserção profissional, a partir da compreensão da complexidade das práticas institucionais e das atividades realizadas pelos profissionais da educação. Em outras palavras,

o Estágio Supervisionado não pode se configurar como espaço isolado, fechado em si mesmo e desarticulado do restante do curso, mas sim como espaços em que os professores em formação vão colocando em uso os conhecimentos que aprendem, ao mesmo tempo em que possam mobilizar outros, de diferentes naturezas e oriundos de diferentes experiências, nos diferentes tempos e espaços curriculares (SBEM, 2003, p. 22).

Nesse sentido, levando-se em consideração a compreensão de como o Estágio Curricular Supervisionado pode, efetivamente, contribuir para a formação do futuro professor que ensina Matemática é que investigamos as pesquisas que tratam dessa temática.

\footnotetext{
${ }^{7}$ A partir de agora, ao usarmos o termo "Estágio" estaremos nos referindo ao Estágio Curricular Supervisionado.
} 
Além desta introdução, na qual apresentamos o objetivo principal da pesquisa, bem como algumas considerações iniciais, este texto foi organizado em mais três partes. A primeira relata o percurso metodológico e, em seguida, a partir dos aspectos relacionados aos objetivos, aos resultados e às conclusões das pesquisas localizadas, traz uma seção de reflexão acerca das diferentes formas com que as pesquisas investigam o Estágio e sua relação com a formação de licenciandos. A terceira e última parte refere-se às considerações finais, elaboradas com base em uma análise das dissertações e teses identificadas.

Traçamos, assim, uma forma de produzir dados relacionados ao nosso objeto de pesquisa, o Estágio Curricular Supervisionado realizado pelo futuro professor que ensina Matemática.

\section{O caminho percorrido...}

Adotamos o estado da arte como metodologia descritiva de caráter inventariante da produção acadêmica, tomando por base os estudos realizados por Ferreira (2002), , Fiorentini et al. (2002), Romanowski e Ens (2006).

O estado da arte é uma metodologia de caráter bibliográfico,

tem desafio de mapear e de discutir uma certa produção acadêmica em diferentes campos do conhecimento, tentando responder que aspectos e dimensões vêm sendo destacados e privilegiados em diferentes épocas e lugares, de que formas e em que condições têm sido produzidas certas dissertações de mestrado, teses de doutorado, publicações em periódicos e comunicações em anais de congressos e de seminários (Ferreira, 2002, p. 257).

Romanowski e Ens (2006) ressaltam a importância de realizar estudos com este tipo de metodologia, pois, segundo as autoras, são uma contribuição importante,

na constituição do campo teórico de uma área de conhecimento, pois procuram identificar os aportes significativos da construção da teoria e prática pedagógica, apontar as restrições sobre o campo em que se move a pesquisa, as suas lacunas de disseminação, identificar experiências inovadoras investigadas que apontem alternativas de solução para os problemas da prática e reconhecer as contribuições da pesquisa na constituição de propostas na área focalizada (Romanowski \& Ens, 2006, p. 39).

A delimitação de nosso corpus de análise partiu das 858 dissertações e teses brasileiras desenvolvidas em programas de pós-graduação stricto sensu nas áreas de Ensino e Educação da Capes, no período de 2001 a 2012, que abordam temáticas relacionadas ao professor que ensina Matemática, mapeadas pelo projeto já citado ${ }^{8}$. Partimos das informações da planilha geral e dos formulários do projeto, buscando identificar, por meio dos títulos e das palavras-chave, pesquisas que se referiam à formação inicial no contexto da Licenciatura em Matemática. Posteriormente procedemos à leitura dos resumos daquelas que julgávamos tratarem da temática. Nesse processo identificamos 208 investigações. A partir daí, nosso

\footnotetext{
${ }^{8}$ Ver: Fiorentini, D.; Passos, C. L. B. \& Lima R. C. R. (org.) (2016). Mapeamento da pesquisa acadêmica brasileira sobre o professor que ensina Matemática: Período 2001 - 2012. FE-Unicamp: Campinas, E-book (no prelo).
} 
segundo refinamento centrou-se naquelas que tinham como foco a formação didáticopedagógica do licenciando. Do resultado dessa segunda busca, foram selecionados 53 trabalhos.

Após uma nova leitura cuidadosa dos formulários dessas 53 pesquisas, optamos por focar nas 20 que tratam do Estágio Curricular Supervisionado na formação do professor de Matemática dos anos finais do Ensino Fundamental e do Ensino Médio.

Posteriormente a essa seleção, iniciamos a leitura dos trabalhos, com o objetivo de estabelecer as categorias de análise. Foram criadas cinco categorias: A) Estágio Curricular Supervisionado: metodologias de ensino em foco; B) Organização e desenvolvimento do Estágio Curricular Supervisionado; C) O Estágio Curricular Supervisionado como espaço de aprendizagem da docência; D) O Estágio Curricular Supervisionado como espaço de reflexão e construção de saberes docentes; e E) O papel do Estágio Curricular Supervisionado na identidade profissional.

Essas categorias foram definidas a partir das temáticas identificadas na leitura das vinte pesquisas. Embora todos os trabalhos tivessem como objeto de estudo o Estágio, as delimitações dos temas de cada um deles possibilitaram realizar agrupamentos entre focos comuns o que permitiu analisar e discutir melhor seus resultados e contribuições acadêmicas.

No Quadro 1, a seguir, apresentamos as pesquisas identificadas que têm como foco os Estágios dos cursos de Licenciatura em Matemática, cujas referências completas podem ser encontradas em Fioretini et al (2016).

Quadro 1: Corpus desta pesquisa e as categorias de análise

\begin{tabular}{|c|c|c|}
\hline \multicolumn{2}{|r|}{ Categorias } & Pesquisas \\
\hline A & $\begin{array}{l}\text { Estágio Curricular Supervisionado: } \\
\text { metodologias de ensino em foco }\end{array}$ & Voigt (2004), Almeida (2009), Proença(2012) \\
\hline B & $\begin{array}{l}\text { Organização e desenvolvimento do Estágio } \\
\text { Curricular Supervisionado }\end{array}$ & $\begin{array}{c}\text { Ludwing (2007), Teixeira (2009), Carvalho } \\
\text { (2010), Feldkercher (2011) }\end{array}$ \\
\hline $\mathrm{C}$ & $\begin{array}{l}\text { O Estágio Curricular Supervisionado como } \\
\text { espaço de aprendizagem da docência }\end{array}$ & $\begin{array}{c}\text { Castro (2002), Lopes (2004), Mendes (2004), } \\
\text { Passerini (2007), Gosmatti (2010), Nonato } \\
\text { (2011), Ribeiro (2011) }\end{array}$ \\
\hline $\mathrm{D}$ & $\begin{array}{l}\text { O Estágio Curricular Supervisionado como } \\
\text { espaço de reflexão e construção de saberes } \\
\text { docentes }\end{array}$ & $\begin{array}{l}\text { Lima (2008), Ferreira (2009), Cruz (2010), } \\
\text { Magalhães (2010), Medeiros (2010) }\end{array}$ \\
\hline $\mathrm{E}$ & $\begin{array}{c}\text { O papel do Estágio Curricular Supervisionado } \\
\text { na identidade profissional }\end{array}$ & Carvalho (2012) \\
\hline
\end{tabular}

Fonte: Dados da pesquisa

Com base nesta categorização, efetuamos a descrição e a análise dos trabalhos, destacando objetivos, principais resultados e conclusões apresentados em cada um deles.

\section{Reflexões sobre as pesquisas}

\section{A. Estágio Curricular Supervisionado: metodologias de ensino em foco}


Do corpus da pesquisa, duas dissertações de mestrado acadêmico (Voigt, 2004; Almeida, 2009) e uma tese de doutorado (Proença, 2012) enfocaram as questões relacionadas às metodologias de ensino e o seu desenvolvimento no Estágio curricular supervisionado do curso de Licenciatura em Matemática. Os três trabalhos que compõem essa categoria abordam as seguintes metodologias de ensino: as Tecnologias da Informação e Comunicação (TIC), a modelagem matemática e a resolução de problemas.

O primeiro, escrito por Voigt (2004), buscou identificar facilidades e dificuldades que o professor de prática de ensino encontra, ao planejar e realizar aulas para os professores em formação no Curso de Licenciatura em Matemática. Essa análise se deu, por um lado, a partir da realização de tarefas destinadas ao ensino de quadriláteros, planejadas pelo professor formador, com o uso do software Cabri-Géomètre II; e, por outro, com o planejamento e o desenvolvimento de aulas pelos estagiários, utilizando-se do mesmo software. Os principais resultados da pesquisa ressaltam que o estudante, ao utilizar um software, poderá elaborar suas conjecturas e confirmá-las ou não. Além disso, destacam o uso das TIC como um instrumental importante a ser integrado na prática de ensino e no Estágio Curricular Supervisionado nos cursos de Licenciatura em Matemática. Outro aspecto de destaque é a evidência que um ambiente informatizado pode assumir um contexto inovador, em especial se possibilitar que o professor e o aluno produzam conhecimento matemático próprio e desenvolvam estratégias próprias, trabalhando cooperativamente.

O segundo trabalho buscou compreender a importância, para o futuro professor, das atividades que envolvem a modelagem matemática durante sua formação inicial. Almeida (2009) acompanhou o desenvolvimento de ações realizadas nessa perspectiva durante o Estágio de licenciandos em Matemática. O autor constatou que os saberes evidenciados durante o desenvolvimento das atividades foram gerados e validados em situações de sala de aula e, portanto, nos momentos de reflexões sobre as ações desenvolvidas. Assim, o estagiário, ao refletir sobre seus saberes disciplinares e curriculares, adquire um saber único, idiossincrático, relacionado aos saberes experienciais, oriundos da prática docente e gerados no cotidiano da sala de aula. Concluiu que o Estágio supervisionado se constitui como um espaço no qual os futuros professores podem ser encorajados a utilizar metodologias diferenciadas e, dessa forma, têm a oportunidade de vivenciar experiências inovadoras, que rompam com os modos tradicionais de ensinar matemática.

Por fim, o último trabalho deste conjunto, de autoria de Proença (2012), propôs-se a investigar questões relacionadas à formação inicial do futuro professor de Matemática e à resolução de problemas. Ao acompanhar o processo de formação no contexto do Estágio Curricular Supervisionado, apontou para a importância da parceria entre o professor formador e o professor da escola básica. Essa parceria permite que os futuros professores aprendam com os docentes da escola-campo aspectos da profissão professor, propiciando, assim, a articulação entre teoria e prática, já que na universidade pode ser oportunizada a reflexão sobre o trabalho realizado com a resolução de problemas. 
Entre os principais resultados, se destaca a afirmação de que não existe uma política clara que favoreça a parceria entre universidade e escola; que garanta um espaço-tempo comum para o trabalho dos professores formadores e dos professores da escola de Educação Básica; e propicie uma interação que permita discussões sobre a dinâmica do Estágio e sobre o papel que, dentro dela, cabe a cada um.

De um modo geral, os resultados dessas três investigações revelam que o Estágio deve ser compreendido como um espaço para vivências de práticas diferenciadas e inovadoras e que a adoção explícita de um referencial metodológico para a organização do ensino pode trazer benefícios claros para a formação do estagiário do curso de licenciatura em Matemática. Nessa direção, nos reportamos a Pimenta e Almeida (2014), que compreendem o Estágio como um momento privilegiado para a formação de futuros professores, por propiciar sua aproximação com o ambiente de trabalho. Contudo, sabemos que uma real interação com o campo profissional exige que os licenciandos se aproximem da prática de profissionais mais experientes, reflitam, analisem, conceituem, busquem articular as teorias estudadas com as situações vivenciadas na prática. Concluindo, as pesquisas que elencamos nesta categoria nos mostram possibilidades para organizar os Estágios de forma a repensar e redirecionar essa etapa importante da formação inicial do docente que ensina Matemática.

\section{B) Organização e desenvolvimento do Estágio Curricular Supervisionado}

Destacamos quatro investigações que voltaram seu foco para o processo de organização e desenvolvimento do Estágio Curricular Supervisionado, assim como para as situações vivenciadas em sua realização. Todos os trabalhos identificados nesta categoria Ludwing (2007), Teixeira (2009), Carvalho (2010) e Feldkercher (2011) - foram realizados em nível de mestrado acadêmico, embora com diferentes estratégias, recursos metodológicos diversos e distintos contextos.

Ludwing (2007) teve como intuito investigar as situações vivenciadas por estagiários de um Curso de Licenciatura em Matemática. Ao acompanhar as disciplinas de Estágio Curricular Supervisionado III e IV e as ações realizadas no âmbito escolar por quatro estagiários, o autor constatou, de forma geral, que eles enfrentavam medos e insegurança, relacionados, principalmente, às suas emoções, aos seus sentimentos ou, ainda, aos obstáculos que as escolas colocavam para suas ações. Observou que os acadêmicos eram influenciados pelo modo de ensino tradicional ministrado nas escolas em que estavam estagiando, apesar das orientações recebidas dos supervisores, que buscavam favorecer uma sólida formação metodológica dos acadêmicos e forneciam subsídios para futuras ações pedagógicas e metodologias de ensino. Ao comparar as concepções dos licenciandos antes e depois do Estágio, Ludwing destacou mudanças relacionadas à humanização da figura do professor e a necessidade de buscar aprendizados relativos à sua profissão e às suas atribuições.

Teixeira (2009) propôs-se a investigar a elaboração do relatório de Estágio supervisionado na formação inicial de professores de Matemática por estudantes de um curso 
de Licenciatura em Matemática. O autor evidenciou que o relatório pode ser importante instrumento, na medida em que proporciona aos futuros professores: 1) refletir sobre as experiências de docência vividas durante o Estágio e autoavaliar-se; 2) desenvolver uma postura investigativa em relação a sua prática; 3 ) reconhecê-lo como elemento de pesquisa; 4) exercitar a escrita discursiva, expressando de forma crítica e reflexiva suas ideias; 5) produzir sentidos para conceitos e ideias matemáticas durante sua elaboração. Ao concluir, Teixeira reitera o potencial formativo do relatório no desenvolvimento profissional de futuros professores de Matemática em formação inicial.

A pesquisa de Carvalho (2010) buscou analisar o Estágio Curricular Supervisionado de alunos do curso de Licenciatura de Matemática de uma instituição pública, a partir da leitura do Projeto Pedagógico do curso e de entrevistas com a professora coordenadora do curso, com a professora coordenadora do Estágio e com duas estudantes. Em relação ao Projeto Pedagógico, os resultados do trabalho evidenciaram que a grade curricular é flexível, com foco direcionado à formação profissional e oferecimento de disciplinas optativas que permitem a aplicação do conhecimento, tanto da Matemática como profissional. As considerações da coordenadora do curso destacam que o Estágio revelou a importância da parceria entre os professores da Universidade e os da escola básica, e que o Estágio é o elo principal entre esses dois contextos. Por fim, as respostas dos estudantes do curso apontaram dificuldades relacionadas à localização das escolas e à falta de flexibilidade de horários. E revelaram que a concepção de bom professor está distante das realidades encontradas nas escolas.

Feldkercher (2011) investigou como se desenvolvem os Estágios nos cursos de Licenciatura em Matemática a distância e presenciais de uma universidade federal, na perspectiva de professores orientadores, coordenadoras de polo e alunos estagiários. A partir da análise de entrevistas com os sujeitos, destacou que: há semelhança na organização curricular dos Estágios nos dois cursos; os estagiários do curso a distância são mais assessorados do que os do presencial, quanto à orientação e ao acompanhamento de suas ações; os estagiários entendem o Estágio como momento de colocar em prática as teorias estudadas, aproximando-os do seu futuro campo de atuação. Verificou, ainda, a existência de inúmeras questões que limitam o desenvolvimento do Estágio nos dois cursos, como a locomoção até a escola, a diferença entre os calendários da universidade e das escolas; e ressaltou que existem mais convergências do que divergências entre os cursos presencial e a distância no desenvolvimento do Estágio Curricular Supervisionado.

Embora as pesquisas tenham sido desenvolvidas de formas distintas, para entender como se desenvolve o Estágio - em seus diferentes contextos -,é preciso considerar que os resultados indicam, de modo geral, dois aspectos importantes: a concepção de Estágio como espaço de indissociabilidade entre teoria e prática, que apresente de modo articulado, a sua dependência fundamental para os futuros professores; e a compreensão, pelos acadêmicos entrevistados, das condições subjetivas e objetivas que permeiam o movimento de aprendizagem da docência no âmbito do Estágio (tais como medos, inseguranças, problemas 
estruturais, localização das escolas, falta de flexibilidade de horários, elaboração dos relatórios de Estágio).

Tais resultados nos mobilizam a refletir sobre a importância de que as propostas e as concepções de Estágio Curricular Supervisionado dos cursos de licenciatura devem estar bem claras e definidas, de modo a efetivamente se constituir, de acordo com as Diretrizes Curriculares Nacionais para a formação inicial em nível superior (Resolução CNE/CP 2/2015), em um componente obrigatório da organização curricular das licenciaturas, uma atividade específica intrinsecamente articulada com a prática e com as demais atividades de trabalho acadêmico (Resolução CNE/CP 2/2015, Art.15, parte III, parágrafo 6.). Isso porque, de acordo com o estudo de Gatti, Nunes, Gimenes, Tartuce, \& Unbehaum (2008), é nas atividades e nas disciplinas de Prática e Estágio que

serão desenvolvidas e discutidas as competências e habilidades para que o futuro professor possa elaborar propostas efetivas de ensino-aprendizagem de Matemática para a sua atuação na Educação Básica, entende-se que a clareza e objetividade nos projetos pedagógicos dos cursos de Licenciatura em Matemática nessas disciplinas/atividades deixa muito a desejar. (p. 76)

Desse modo, muitas fragilidades estão relacionadas à prática e ao Estágio nos cursos de Licenciatura em Matemática e merecem maior atenção na análise da maneira como está sendo realizada a formação de professores.

\section{C) O Estágio Curricular Supervisionado como espaço de aprendizagem da docência}

Em relação à constituição do Estágio Curricular Supervisionado como um movimento formativo e espaço de aprendizagem da docência, com destaque para seu papel na definição da escolha da profissão, localizamos sete pesquisas. Em nível de mestrado acadêmico, há cinco dissertações: Castro (2002), Mendes (2004), Passerini (2007), Gosmatti (2010) e Nonato (2011), e em nível de doutorado, duas teses: Lopes (2004) e Ribeiro (2011).

A pesquisa de Castro (2002), cujo objetivo foi investigar como acontece o processo de formação do professor de Matemática em saberes, ações e significados, quando, no trabalho com as disciplinas de Prática de Ensino e Estágio Supervisionado, ele entra em contato com a atividade docente na escola, identificou nos futuros professores diversas evidências formativas. Dentre elas, ressalta a ressignificação - ocorrida logo ao começarem a ensinar das experiências e dos modelos ou imagens sobre como deve ser a gestão do ensino, internalizados durante a vida estudantil. Castro constatou também a complexidade do campo de trabalho do professor, a importância de continuar estudando e o quanto ele precisa do outro para partilhar os saberes que produz. E ressaltou que a Prática de Ensino e o Estágio não podem ocorrer apenas no final do curso de licenciatura, pois se configuram como momentos fundamentais de formação e de desenvolvimento profissional, e não como simples instâncias de treinamento ou aplicação prática de modelos apreendidos anteriormente.

Também com o objetivo de investigar o processo de formação do professor de Matemática, Mendes (2004) direcionou seu olhar para um grupo de alunos da disciplina de Prática de Ensino que realizavam Estágio Supervisionado. E relata que os futuros professores 
compreendem a Prática de Ensino e Estágio como uma etapa da sua formação em que ocorrem aprendizagens relativas não apenas às questões didáticas e metodológicas, mas também à maneira de se relacionar com os alunos. Contudo, ressalta que o caráter complementar conferido à Prática de Ensino e ao Estágio Supervisionado nos cursos de Licenciatura - pois a teoria é apresentada no início e a prática, colocada no final dos cursos representa um obstáculo à formação dos futuros professores. De acordo com o autor, os discursos dos sujeitos participantes da pesquisa evidenciaram não apenas a dicotomia entre teoria e prática em seus cursos de formação inicial, mas também a ausência de um trabalho pedagógico e epistemológico dos conteúdos.

Passerini (2007) investigou o papel do Estágio Supervisionado na formação inicial do professor de matemática, na ótica dos licenciandos em matemática. Com base em seus resultados, aponta para a necessidade de discutir, no curso de formação inicial, fatores que dificultam a implementação de práticas inovadoras nas escolas e também de viabilizar a aproximação com o ambiente e as condições de trabalho. Destaca que, para os cursos de Licenciatura em Matemática, é um desafio implementar propostas em que todas as disciplinas, e não apenas as pedagógicas, tenham dimensão prática, conforme propõem as Diretrizes Curriculares. Constatou que, para os que ainda não trabalhavam como professores, as ações e o processo de reflexão mobilizado pelo Estágio constituíram sua primeira oportunidade de atuar como educadores, enfrentar desafios de planejar aulas, de relacionar-se com alunos, de avaliar sua aprendizagem. E, para aqueles que já haviam trabalhado ou estavam trabalhando como professores, o Estágio possibilitou conhecer diferentes métodos de ensino e refletir sobre sua prática docente.

Procurando desvelar como professores de Estágio Curricular Supervisionado de cursos de Licenciatura em Matemática entendem a prática de ensino, ao elaborarem e desenvolverem atividades em disciplinas de Estágio Curricular Supervisionado, Gosmatti (2010) apresentou os projetos pedagógicos e as ementas de disciplinas de cursos de Licenciatura em Matemática de duas instituições e realizou entrevistas semiestruturadas com professores de Estágio Curricular Supervisionado desses cursos. Os resultados da pesquisa levaram o autor a afirmar que o Estágio, a partir das ações docentes e discentes, pode proporcionar transformações na realidade, tais como a própria aprendizagem da docência no processo de constituição da identidade docente pelo aluno/estagiário. Ressalta que a atividade deste na escola, desde que planejada a partir da investigação da práxis docente escolar, intervém nela e pode proporcionar transformações na realidade, ou seja, na aprendizagem por parte dos alunos escolares; na aprendizagem da docência pelo próprio aluno/estagiário; ou, ainda, em um novo posicionamento do professor escolar quanto à sua prática. Conclui, afirmando que a práxis envolve tanto a prática de ensino do professor de Estágio como a prática do estagiário.

Nonato (2011) investigou elementos oferecidos pelo Estágio Supervisionado para o Ensino Médio que contribuem para as aproximações com a prática para o ensino de Matemática e constatou que o Estágio poderia proporcionar novas aproximações de forma 
significativa tanto do ponto de vista de um grupo de professores em processo de formação inicial como de outro, composto por professores já atuantes em classes da Educação Básica. Tomando por base as discussões entre os professores-formadores da disciplina de Estágio, observou que a preocupação excessiva com disciplinas específicas de conteúdo matemático, desvalorizava a disciplina de Estágio que, na sua compreensão, deveria ocupar um lugar central no currículo de um curso de formação de professores. Para o autor, o que gerou maiores contribuições para a formação dos futuros professores foram as aulas que envolveram atividades práticas do oficio docente, bem como a presença, na escola, dos estagiários e dos professores formadores, que já conheciam essa realidade e puderam apontar se as atividades foram ou não ao encontro da realidade docente.

Lopes (2004) investigou o processo de formação de futuros professores, observando como ocorrem suas aprendizagens docentes em um processo de Estágio com atividades compartilhadas. Concluiu que a socialização de diferentes momentos do desenvolvimento do Estágio permitiu que as ações pudessem ser compartilhadas e avaliadas de modo a determinar novas ações, com novas qualidades, e o desenvolvimento coletivo das atividades contribuiu para a reconfiguração dos motivos dos estagiários, pois a reflexão sobre as ações desenvolvidas possibilitou a tomada de consciência. Esse movimento levou os estagiários a constatar que ser professor que ensina matemática exige conhecimento dos conteúdos dessa disciplina, mas só isso não garante a aprendizagem do aluno. $\mathrm{O}$ pesquisador aponta que a organização do ensino pelo estagiário pode levar a atividade de ensino (do professor) a concretizar-se em atividade de aprendizagem (para o aluno). E, assim, algumas ações, como o planejamento, a avaliação e o registro, tornam-se particularmente significativas.

Procurando indicadores de um movimento formativo na direção da práxis do futuro professor de Matemática, que conduza à formação do seu pensamento teórico para a docência, Ribeiro (2011) buscou evidenciar o modo como o sujeito vai se constituindo professor no desenvolvimento das disciplinas de Prática de Ensino e de Estágio Supervisionado. Os resultados da investigação levaram a autora a identificar que a relação entre o professor orientador no campo de Estágio e o professor formador na universidade é muito importante e deve superar o mero consentimento, pelo professor da escola, para que os futuros professores desenvolvam as atividades de Estágio. Mais do que isso, é preciso também que o orientador conheça a proposta formativa e seus referenciais teóricos, para melhor compreender seu papel de mediador na apresentação de situações desencadeadoras de ensino; para mobilizar os estudantes a realizar atividades de ensino significativas.

Em comum, as pesquisas apontam o Estágio como espaço que proporciona a relação entre teoria e prática e como um dos momentos mais importantes para a formação do futuro professor. Além disso, da forma como as propostas pesquisadas se organizaram, o mesmo se constituiu como um espaço de reflexão, embora esse não fosse o foco de investigação inicial.

Os resultados apresentados chamam a atenção para a inadequação com que muitas vezes o Estágio é tratado nos cursos de licenciatura. Gatti et al. (2008) questionam as condições em que eles são ali realizados. Lembram que o número de horas de Estágio 
obrigatório visa proporcionar um contato mais aprofundado com as escolas de educação básica, de forma planejada, orientada e acompanhada de um professor-supervisor. Admitem que, em princípio, eles constituam espaços privilegiados para a aprendizagem das práticas docentes. Contudo, em seus estudos, não obtiveram evidências sobre como vêm sendo de fato realizados, o que revela a importância das pesquisas, cujos resultados podem nos auxiliar a compreender o que acontece nesses espaços de formação mas não está expresso nos currículos documentados.

D) O Estágio Curricular Supervisionado como espaço de reflexão e construção de saberes docentes

Dentre as experiências vivenciadas por professores em sua formação, o Estágio é, sem dúvida, um espaço rico de vivência da prática docente, no qual ocorrem reflexões e aprendizagens de novos saberes. As pesquisas deste corpus de análise que versam sobre saberes docentes apontam o Estágio como um espaço de reflexão que leva à construção de saberes docentes, base para o ensino e a aprendizagem da Matemática. Cinco são os estudos que trazemos nesta categoria, nos quais o Estágio tem papel central na construção dos saberes para a docência. Três deles são de mestrado acadêmico (Lima, 2008; Magalhães, 2010; Medeiros, 2010) e dois são de doutorado (Ferreira, 2009; Cruz, 2010).

Lima (2008) discutiu as possibilidades de desenvolvimento de práticas colaborativas no Estágio Curricular Supervisionado em Matemática, considerando as interações existentes na tríade licenciando/professor-formador/professor-escolar e concebendo o Estágio como um elo entre a escola e a universidade. As conclusões do autor apontam: 1) a necessidade de superar as práticas baseadas numa pedagogia de supervalorização dos saberes disciplinares da Matemática, em detrimento das outras formas de saber; 2) a opção de construir coletivamente os saberes da ação pedagógica - muito mais pela possibilidade de validar experiências vividas no Estágio; 3) a importância de pensar e analisar criteriosamente os aspectos metodológicos do Estágio dentro da escola, com o intuito de eliminar a ideia corrente de que ele é simplesmente a hora da prática.

Centrar a formação em um dos tipos de saberes: disciplinares ou pedagógicos é apontado por Shulman (1986, p. 7) como um "paradigma perdido". Ao discutir a base de conhecimento para o ensino, ele ressalta a importância de novas formas de construção dos saberes da docência e pontua que a prática educativa deve estar embasada em determinados conhecimentos, que servirão como alicerces para a construção de um saber necessário ao exercício da profissão docente. Um deles é o conhecimento pedagógico do conteúdo, que vai além do conhecimento do conteúdo em si e atinge a dimensão do conhecimento disciplinar para o ensino.

Com esse mesmo enfoque, Lima (2008) chamou a atenção para as possibilidades de produção e sistematização de conhecimentos, num movimento que dê sentido àquilo que é produzido tanto na escola quanto na universidade Isso requer a criação e a recriação dos saberes experienciais, em um coletivo de profissionais que discutam os problemas 
conjuntamente; institucionalizem práticas, atitudes e crenças que possibilitem a todos compreender os saberes da ação pedagógica.

Ferreira (2009) explorou as interações discursivas vivenciadas pelos licenciandos no Estágio Supervisionado, em termos da construção dos saberes docentes desses futuros professores de Matemática. Os resultados de pesquisa apontaram que o Estágio Curricular Supervisionado é visto como um processo que auxilia o licenciando na familiarização com a sala de aula, pois retrata uma face do ambiente de trabalho.

Para Mizukami (2004), o saber advindo da experiência, neste caso a do Estágio, influi no desenvolvimento da prática docente, ao defender que se considere o conhecimento da experiência como base do conhecimento, uma vez que esta se faz presente em todo o processo de raciocínio pedagógico, sendo condição necessária, mas não suficiente, para a construção, pelo docente, do conhecimento pedagógico do conteúdo.

A experiência do Estágio na pesquisa de Ferreira (2009) propiciou aos futuros professores reflexões sobre estratégias didático-metodológicas relacionadas ao ensino e à aprendizagem da Matemática, saberes necessários para o ensino, e mobilizou e produziu outros saberes fundamentais à formação desses futuros professores, atuando em seu desenvolvimento profissional.

Magalhães (2010) também vai nessa direção, ao verificar se a proposta de Estágio supervisionado dos cursos de Licenciatura em Matemática de uma instituição tem provocado uma prática reflexiva nos alunos e investigou que tipo de reflexões o Estágio propicia.. A autora concluiu que um dos entraves para que ocorra o processo de reflexão é a pouca interação entre os professores do curso, o professor de Estágio e os alunos, além da falta de espaços para orientação de estagiários e discussões coletivas. Caracterizou o processo de reflexão em três níveis gradativos de complexidade. A reflexão técnica refere-se a uma reflexibilidade bastante imediata, que tem sua origem na experiência, relacionada às idéias genuínas da docência; a reflexão prática situa-se na interação recíproca entre o conhecimento científico e o conhecimento pessoal e o nível de reflexão crítica que implica a análise ética, social e política da própria prática. Considerando que o objetivo dessa investigação não era enquadrar o Estágio em um nível de reflexão, mas verificar quais aspectos de cada nível perpassaram as propostas, a autora concluiu que as propostas curriculares dos cursos e o discurso e a prática dos professores evidenciam uma reflexão prática. Nessa reflexão, os métodos científicos servem de parâmetros para analisar a prática, porém a prática dos professores não inclui, necessariamente, uma relação dialética entre teoria e prática. Por isso, o processo de pesquisa sobre a prática ainda é incipiente. Apesar desse nível de reflexão ser o vigente, vislumbraram-se entre os pesquisados algumas características da reflexão crítica.

Cruz (2010) propôs-se a analisar as potencialidades do Ensino Prático Reflexivo, desenvolvido por meio de ações coletivas, no contexto de um curso de Formação Inicial de Professores de Matemática, durante o Estágio Curricular Supervisionado. Sua pesquisa foi fundamentada nas ideias centrais de Schön (2000), que propõe uma epistemologia da prática 
em que se valoriza a prática profissional como lócus de construção de conhecimento e formação profissional. A partir dos dados coletados, a autora conclui que a proposta do Ensino Prático Reflexivo, quando envolve processos de colaboração em que haja troca de experiências e possibilidade de análise das práticas no coletivo, proporciona que significados sejam construídos. Após a realização da pesquisa, a autora defende um Estágio Supervisionado dentro de uma proposta de Ensino Prático Reflexivo, que incorpore de forma significativa a prática da reflexão no processo formativo do futuro professor de Matemática como uma alternativa para minimizar o choque da realidade.

Medeiros (2010) investigou o processo de desenvolvimento de atitudes, práticas e saberes docentes durante o Estágio Curricular Supervisionado na relação entre professor escolar e estagiário. Ele identificou que os sujeitos da pesquisa assimilaram e construíram saberes docentes durante as atividades curriculares de Estágio: além de aprenderem a refletir diante das mais diversas situações de ensino e aprendizagem da Matemática, perceberam a importância de tornar-se professores pesquisadores, tanto de suas ações pedagógicas quanto das de outros professores. Os resultados da pesquisa demonstraram que o estágio, quando bem direcionado e quando os professores escolares colaboram nas ações pedagógicas dos estagiários no contexto escolar, pode reforçar ou fazer emergir nos estagiários o desejo de assumir a profissão professor, com práticas pedagógicas diferenciadas. Dessa forma, evidencia-se o Estágio como espaço de formação que permite reconstruir os saberes docentes necessários ao processo de ensino e aprendizagem.

Os resultados apresentados por essas cinco pesquisas brasileiras compactuam com estudos que se intensificaram a partir de 1990, principalmente com os trabalhos de Fiorentini (2004, 2006), Nóvoa (1995), Pimenta (2008), Ponte (2002), Schön (2000), Shulman (1986) e Tardif (2002), que apontam a importância de constituir espaços de formação que permitam ao futuro professor uma prática reflexiva e que leve à construção de diferentes saberes, em especial o conhecimento pedagógico ou didático do conteúdo.

\section{E) O papel do Estágio Curricular Supervisionado na identidade profissional}

Dentre as pesquisas que envolvem o Estágio Curricular Supervisionado, identificamos uma investigação em nível de mestrado acadêmico que traz em seu bojo a questão da identidade docente, ou seja, aborda o significado da docência.

Carvalho (2012) tem em sua dissertação a seguinte questão: “A decisão tomada pelo estagiário em querer ser professor de matemática se altera perante as atividades de Estágio Supervisionado?". Por meio dos depoimentos dos alunos, constatou que o Estágio contribuiu para que parte deles mudasse de opinião. As justificativas foram as seguintes: ampliação do campo de trabalho almejado; interesse por outras carreiras profissionais; insegurança quanto a saber o que é ser professor de Matemática. Já os alunos que afirmaram que, após o Estágio, continuam a querer ser professor da Educação Básica, apresentaram as seguintes justificativas: satisfação com a profissão; ações que poderão realizar quando forem professores e que vêm ao encontro das suas expectativas profissionais; e experiências 
vivenciadas durante o Estágio, no qual o futuro professor viu um meio que o levará a ser um bom professor, mesmo admitindo não se sentir preparado para a profissão.

A partir das considerações do autor, podemos destacar em relação a essa pesquisa a oportunidade que o Estágio representa para que futuros professores de matemática possam se aproximar da construção de sua identidade profissional. Além dos interesses e ensejos particulares que direcionam as opções profissionais, ressaltamos as situações de crise, muito comuns nesse momento do curso de licenciatura, onde os acadêmicos passam a refletir sobre suas escolhas profissionais, assim como o significado de ser professor na sociedade atual.

\section{Considerações finais}

Ao olharmos para as pesquisas relacionadas aos cursos de Licenciatura em Matemática, nos propusemos a mapear, descrever e analisar aquelas voltadas ao Estágio Curricular Supervisionado, no que tange aos seus objetivos, principais resultados e conclusões.

Analisando os 20 trabalhos encontrados, inicialmente é possível perceber o aumento das pesquisas sobre esse tema nos últimos tempos, já que, considerando o período de 12 anos a que se refere o presente estudo (2001 a 2012), cinquenta por cento delas foram desenvolvidas nos últimos três anos. Tais investigações, se, por um lado, são distintas na medida em que se constituíram por particularidades e mostram diferentes modos como o Estágio se organiza, por outro trazem considerações que as aproximam.

Os principais avanços que nos apontam as pesquisas, identificados por meio das categorias elencadas, dizem respeito às possibilidades de um modo de compreender o Estágio que vá além de um momento de possível interação entre teoria e prática que acontece somente pelo fato do futuro professor estar em sala de aula. Isso acontece quando apontam a possibilidade de diferentes metodologias e modos de organizar e de desenvolver o Estágio; a compreensão do espaço de aprendizagem da docência que pode ser constituído nesse momento de graduação; o movimento de reflexão e construção de saberes docentes para futuros professores de matemática; e, ainda, a oportunidade de construir a identidade profissional a partir do Estágio Curricular Supervisionado e não somente quando efetivamente se tornar professor, após o curso de licenciatura.

De modo geral, todos os estudos concebem o Estágio como um momento não restrito a uma ação isolada de finalização do curso de licenciatura, em que o futuro professor aplica os conhecimentos teóricos adquiridos ao longo do curso. Antes, sim, apresentam-no como um espaço em que teoria e prática não se dissociam; em que, principalmente, ocorrem aproximação e interação com a Educação Básica, e as possibilidades de diferentes interações são importantes para a aprendizagem de todos os envolvidos.

Destacam que a vivência de experiências inovadoras é relevante para o processo formativo, mas que elas, por si sós, não bastam. Chamaram-nos a atenção para as condições objetivas e subjetivas ou, ainda, para as inadequadas formas como ele é tratado, o que pode influenciar de maneira significativa esse momento e, por conseguinte, as possibilidades de 
aprendizagem do futuro professor. Também nos sugeriram que o Estágio é um espaço primordial para a compreensão da complexidade docente e para a constituição da identidade docente.

Principalmente, os resultados das investigações nos trazem subsídios para discutir a importância da articulação a ser estabelecida entre a escola de Educação Básica e a Universidade, o professor regente e o professor orientador. A compreensão da afinidade dessa relação é primordial para compreendermos o Estágio como um espaço privilegiado de articulação entre teoria e prática na formação do professor e, consequentemente, como meio para a construção de saberes essenciais para a profissão docente.

\section{Referências}

Ferreira, N. S. A. (2002). As pesquisas denominadas "Estado da Arte". Educação \& Sociedade, 23(79), 257-272.

Fiorentini, D. (2004). A didática e a Prática de Ensino mediadas pela investigação sobre a prática. In J. P. Romanowski, P. L. O. Martins, \& S. R. A. Junqueira. (Orgs.), Conhecimento local e conhecimento universal: pesquisa, didática e ação docente (pp. 243-257). Curitiba: Champanhat.

Fiorentini, D. (2006). Pesquisar práticas colaborativas ou pesquisar colaborativamente? In M. C. Borba (Org.), Pesquisa qualitativa em educação matemática (pp.47-76). Belo Horizonte: Autêntica.

Fiorentini, D., \& Castro, F. C. (2003). Tornando-se professor de matemática: o caso de Allan em prática de ensino e estágio supervisionado. In D. Fiorentini (Org.), Formação de professores de matemática: explorando novos caminhos com outros olhares (pp. 121156). Campinas: Mercado de Letras.

Fiorentini, D., Nacarato, A. M., Ferreira, A. C., Lopes, C. S., Freitas, M. T. M., \& Miskulin, R. G. S. (2002). Formação de professores que ensinam Matemática: um balanço de 25 anos da pesquisa brasileira. Educação em Revista, 36, 137-160.

Fiorentini, D.; Passos, C. L. B. \& Lima R. C. R. (org.) (2016). Mapeamento da pesquisa acadêmica brasileira sobre o professor que ensina Matemática: Período 2001 - 2012. FE-Unicamp: Campinas, E-book. Disponível em: https://www.fe.unicamp.br/pffe/pf/subportais/biblioteca/fev-2017/e-book-mapeamento-pesquisa-pem.pdf.

Gatti, B. A. (2012). Políticas e práticas de formação de professores: perspectivas no Brasil. In Anais, 16 Encontro Nacional de Didática e Práticas de Ensino. Campinas, SP.

Gatti, B. A., Nunes, M. M. R., Gimenes, N. A. S., Tartuce, G. L. B. P., \& Unbehaum, S. G. (2008). Formação de professores para o ensino fundamental: instituições formadoras e seus currículos: relatório de pesquisa. São Paulo: Fundação Vitor Civita.

Mizukami, M. G. (2004). Aprendizagem da docência: algumas contribuições de L. S. Shulman. Revista Educação, 29(2), 1-11.

Nóvoa, A. (1995). Os professores e a sua formação. Lisboa: Dom Quixote. 
DOI: http://dx.doi.org/ 10.20396/zet.v25il.8647637

Pimenta, S. G. (2008). Formação de professores: identidade e saberes da docência. In S. G. Pimenta (Org.), Saberes pedagógicos e atividade docente (pp. 15-34). São Paulo: Cortez.

Pimenta, S. G., \& Almeida, M. I. (2014). Estágios supervisionados na formação docente. São Paulo: Cortez.

Ponte, J. P. (2002). Investigar a nossa própria prática. In Grupo de Trabalho sobre Investigação (Ed.). Refletir e investigar sobre a prática profissional (pp. 05-8). Lisboa: APM.

Resolução MEC/CNE (2015, fevereiro). Diretrizes Curriculares Nacionais para a formação inicial em nível superior (cursos de licenciatura, cursos de formação pedagógica para graduados e cursos de segunda licenciatura) e para a formação continuada. Brasília, DF: Conselho Nacional de Educação.

Romanowski, J. P., \& Ens, R. T. (2006). As pesquisas denominadas do tipo "Estado da Arte" em educação. Diálogo Educacional, 6(19), 37-50.

SBEM (2003). Sociedade Brasileira de Educação Matemática. Subsídios para a discussão de propostas para os cursos de Licenciatura em Matemática: uma contribuição da Sociedade Brasileira de Educação Matemática. Brasília, DF. Retirado em 18 de julho de 2016, de: https://www.academia.edu/4256113/subsidios para a discussão de propostas para os cursos de licenciatura.

Schön, D. (2000). Educando o profissional reflexivo: um novo design para o ensino e a aprendizagem. Porto Alegre: Artes Médicas Sul.

Shulman. L. S. (1986). Those who understand: knowledge growth in teaching. Educational Researcher, 15(2), 4-14.

Silva, S. A. F., Vasconcelos, P. B. M., \& Paiva, M. A. V. (2015). O Estágio Supervisionado: uma experiência de aprendizagens docentes na formação do futuro professor de Matemática. In C. S. Lopes, A. Traldi, \& A. C. Ferreira, O estágio na formação inicial do professor que ensina Matemática (pp. 98-114). Campinas: Mercado de Letras.

Tardif, M. (2002). Saberes docentes e formação profissional. Petrópolis: Vozes. 


\section{APÊNDICE 1: Relação das teses e dissertações do corpus de análise deste estudo}

Almeida, R. N. (2009). Modelagem Matemática nas atividades de Estágio: saberes revelados por futuros professores. Dissertação de Mestrado. São Carlos: Universidade Federal de São Carlos.

Carvalho, D. F. (2012). O Estágio Curricular Supervisionado e a decisão do licenciado em querer ser professor de Matemática. Dissertação de Mestrado. Londrina: Universidade Estadual de Londrina.

Carvalho, R. C. B. (2010). O estágio na formação inicial de professores de Matemática na perspectiva de uma universidade pública do estado de São Paulo. Dissertação de Mestrado. São Paulo: Universidade Cruzeiro do Sul.

Castro, F. C. (2002). Aprendendo a ser professor(a) na prática : estudo de uma experiência em prática de ensino de Matemática e estágio supervisionado. Dissertação de Mestrado. Campinas: Universidade Estadual de Campinas.

Cruz, M. A. S. (2010). Uma proposta metodológica para a realização do Estágio Supervisionado em um curso de formação inicial de professores de Matemática: limites e possibilidades. Tese de Doutorado. Campo Grande: Universidade Federal do Mato Grosso do Sul.

Feldkercher, N. (2011). O estágio na formação de professores presencial e a distância: a experiência do curso de Matemática da UFPel. Dissertação de Mestrado. Pelotas: Universidade Federal de Pelotas.

Ferreira, C. M. S. (2009). Um estudo exploratório da construção de saberes docentes provenientes de interações discursivas no estágio curricular. Dissertação de Mestrado. Belo Horizonte: Universidade Federal de Minas Gerais.

Gosmatti, A. (2010). Prática de ensino na perspectiva de professores de Estágio Curricular Supervisionado de Matemática. Dissertação de Mestrado. Curitiba: Universidade Federal do Paraná.

Lima, J. I. (2008). O Estágio Supervisionado na Licenciatura em Matemática: possibilidades de colaboração. Dissertação de Mestrado. Belém: Universidade Federal do Pará.

Lopes, A. R. L. V. (2004). A aprendizagem docente no estágio compartilhado. Tese de Doutorado. São Paulo: Universidade de São Paulo.

Ludwing, P. I. (2007). Formação inicial de professores de Matemática: situações vivenciadas pelos alunos na realização do estágio. Dissertação de Mestrado. Canoas: Universidade Luterana do Brasil.

Magalhães, A. P. A. S. (2010). O Estágio Supervisionado dos cursos de formação de professores de Matemática da Universidade Estadual de Goiás: uma prática reflexiva? Dissertação de Mestrado. Belo Horizonte: Universidade Federal de Minas Gerais. 
DOI: http://dx.doi.org/ 10.20396/zet.v25il.8647637

Medeiros, C. M. (2010). Estágio Supervisionado: uma influência na constituição dos saberes do professor de Matemática na formação inicial. Dissertação de Mestrado. Belém: Universidade Federal do Pará.

Mendes, M. J. F. (2004). Reflexões sobre a formação do professor de Matemática: investigando a prática de ensino no curso de Licenciatura da UFPA. Dissertação de Mestrado. Belém: Universidade Federal do Pará.

Nonato, K. J. (2011). Estágio Supervisionado em Matemática: contribuições para a formações de professores de Matemática. Dissertação de Mestrado. Campo Grande: Universidade Federal do Mato Grosso do Sul.

Passerini, G. A. (2007). O Estágio Supervisionado na formação inicial do professor de Matemática na ótica de estudantes do curso de Licenciatura em Matemática da UEL. Dissertação de Mestrado. Londrina: Universidade Estadual de Londrina.

Proença, M. C. (2012). A resolução de problemas na Licenciatura em Matemática: análise de um processo de formação no contexto do estágio curricular supervisionado. Bauru. Universidade Estadual Paulista.

Ribeiro, F. D. (2011). A aprendizagem da docência na prática de ensino e no estágio: contribuições da teoria da atividade. Tese de Doutorado. São Paulo: Universidade de São Paulo.

Teixeira, B. R. (2009). Registros escritos na formação inicial de professores de Matemática: uma análise sobre a elaboração do relatório de Estágio Supervisionado. Dissertação de Mestrado. Londrina: Universidade Estadual de Londrina.

Voigt, J. M. R. (2004). O Estágio Curricular Supervisionado da Licenciatura em Matemática em um ambiente informatizado: trabalhando com o Cabri-Géomètre II no Ensino Fundamental. Dissertação de Mestrado. Curitiba: Universidade Federal do Paraná. 